\title{
Exploring the nexus between spirituality and health
}

\begin{abstract}
This paper attempts to explore the relationship between spirituality and health Though these are considered two autonomous disciplines, they converge on a holistic understanding of human person who needs to be cared for not merely as a bodily reality but as a animated body or an embodied soul. Hence this paper argues the importance of integrating spirituality into healthcare system based on effectiveness of this as shown by the data of some empirical studies.
\end{abstract}

Keywords: salutogenesis, spirituality, erroneous, autonomy, continuum
Volume 3 Issue 2 - 2018

\author{
Nishant A Irudayadason \\ Faculty of Philosophy, India
}

Correspondence: Nishant A Irudayadason, Faculty of Philosophy, India, E-mail nishant@jdv.edu.in

Received: March 20, 2018| Published: April 6, 2018

\section{Introduction}

In recent years spirituality is recognized as having the potential to prevent, cure or cope with the disease. There is a growing support to the idea that spiritual values and life goals make an undeniable contribution to both physical and mental health. It is important to clarify what we mean by spirituality at the very start. We can do so by first distinguishing the terms religion, religiosity and spirituality. Religion covers a structured way of believing in a system with the existence of beliefs that a person asserts, norms of behaviour that define his/her membership and prescribed rituals. ${ }^{1}$ Religiosity is understood as the set of practices experienced by a person within a given religion. Spirituality is broader than these two concepts. It encompasses the meaning of existence, the presence of being-in-theworld, experience of interconnectedness and inner peace. ${ }^{2}$ In other words, religion and religiosity are not sufficient to define spirituality and it can be said that every person has a spiritual dimension, whether or not he or she has a religious affiliation. It is now recognized and accepted by many thinkers that the term spirituality is broader than religion. As Sulmasy aptly notes, "although not everyone has a religion, everyone who searches for ultimate or transcendent meaning can be said to have a spirituality. ${ }^{1}$ " Whether one denies or accepts the fact, spirituality is a constituent and intrinsic element to the human person who seeks to unify his or her life experience in self-realization. Jean-Claude Breton holds that the spiritual life responds to the needs of a person and relies on the reality of the person more than it comes under the authority or the imperative of religion. ${ }^{2}$ Can we really ignore a religious denomination when we want to meet the spiritual needs of a sick person? This is a problem that arises in hospital environments of Judeo-Christian tradition that wonder if doctors and nurses of Christian faith must opt for an approach faithful to their faith tradition. Some support a description of spirituality and spiritual life marked by adherence to the Christian faith, because spirituality must be embodied and rooted in a soil inherited from our ancestors in faith. ${ }^{3}$ Unlike Fawcett and Noble, Antonia M. van Loon, favours an expanded description of spirituality and spiritual care because, in her view, "a unilateral Christian definition in a pluralist society would be an infringement of human rights and would most likely curtail current nursing practice. I prefer to live with ambiguity and question marks around this dimension, thereby allowing leeway to explore with the patient, what their needs might be in every dimension of care, rather than think I can provide a 'cure' to spiritual needs, as
Fawcett and Noble boldly claim". ${ }^{4}$ When we witness a disassociation from religious tutelage, it does not mean a lack of spiritual interest. Some go so far as to propose a secular spirituality. ${ }^{5}$ It is necessary to dismiss from the outset the erroneous assertion that, if a person does not belong to a religious group, he or she is not spiritual. It is essential to understand the latent and unexpressed thirst among the sick find ways to join the spiritual core. Placed in front of the great existential limits of suffering, sickness, time and death, sick people wait in their spiritual quest not so much for answers as for comfort. More than ever, in the secular and pluralistic context of our society, we must allow ourselves to be challenged by the meeting of spirituality across borders and discover the treasures that are often hidden.

\section{Significance of spirituality in the wake technological approach to health}

Many establish a close correlation between spirituality and health. Others want these disciplines to keep their autonomy and maintain a distinction or even a separation between these fields of human reality. Several factors may explain the growing interest in making spiritual concerns present in health care and services. According to Astrow, Puchalski and Sulmasy, the two main factors are: 1.the recognition of the limits of scientific approach to medical care which cannot solve the mystery of suffering and which seems to have reduced the patient to an object of analysis and research; 2. Serious scientific studies have demonstrated the beneficial effects of religious practice and spirituality on health. ${ }^{6}$ Technology has made an extraordinary progress in diagnosis and treatment of diseases. We can applaud the rise of contemporary medicine and hope that advances in medical research translate into therapeutic applications to benefit the entire world. However, this techno-scientific development of medicine has rationalized disease so much that it fails to treat the sick persons in their singularity as unique. It has also created a scientific fundamentalism that wants to be manipulator of the significant realities of birth and death. Based on the studies of oncologist Harald Theml, Michael Nüchtern asserts that in its history and practice, medicine has manifested universal claims to a growing objectivization, a technologizing and specialization of medicine; the more modern medicine is able to respond to health needs, the more it acts as a power on which one becomes dependent. ${ }^{7}$ This global claim has been put to the test by the inability of scientific medicine to respond to new diseases and epidemics, such as AIDS, and by the craze of our contemporaries for alternative therapeutic 
methods, a cultural phenomenon that is uncomfortable with traditional scientific medicine. Too limited in the measurable and the objectifiable and excluding as unreal what does not fall into these categories, based on a reductionist concept of health and illness, scientific medicine has put on the back-burner questions about the meaning of life and the personal and collective visions of life. The scientific vision of medicine has faced serious limitations such as the exorbitant cost of technologically advanced new treatments and the exclusion of the poor. ${ }^{8}$

Unable to respond to the hopes of cure and challenged by alternative therapeutic approaches on notions of health, illness and healing, scientific medicine, the techno-scientific medicine maintains silence on fundamental existential questions. Hence spirituality with its vision the caring-nurtured relationship needs to be an integral part of the healing process of the person understood in a broad and encompassing sense of mind-body-soul harmony. The introduction of the concept of "total pain" by Cicely Saunders has obliged health professionals to treat not only the physical dimension of pain, but also the psychosocial and spiritual dimension of suffering. ${ }^{9}$ This provoked a profound re-examination of medical practice and brought back a spiritual quest and desire to the consciousness of caregivers and sick people. Medical practice and research can offer us invaluable help in ensuring that every human person has a decent material condition and a quality of life. However, not everything can be implemented, and we must not reduce the life of the human person to his or her physical dimension. The human person is also a spiritual being in search of meaning and fulfilment. It is only in the consideration of this spiritual thirst and the finitude of the human person, expressed visibly in sickness and death, that medicine can really help it in his or her emotional and spiritual maturation. ${ }^{10}$ Historically, religion has been linked to health. The history of religions shows us how religion has been a fundamental source of medicine. As Bernard Ugueux observes, medicine and religion are the two great social institutions that manage what has haunted humanity since its origins: the preserving and transmitting human life that is fulfilled, and fruitful in a positive relationship with other humans, cosmos and the divine. ${ }^{11}$ According to Raimon Panikkar, by confusing religion with medicine, medicine is crippled, and religion is deformed, but, by dissociating medicine from religion, the former is degraded, and the latter is alienated..$^{12}$ Ian G. Barbour presents four ways in which the relationship between science and religion is expressed:

i. Antagonism: both seeking to deny mutually their claim to the truth.

ii. Autonomy: each keeping its own area of expertise, science dealing with the body and religion with the soul.

iii. Dialogue: both collaborate on common topics of reflection and research.

iv. Integration: much of the current research on the link between spirituality and health is in the form of dialogue and integration. ${ }^{13}$

Thus, the relationship between spirituality and health must be considered, not as two separate and independent disciplines, but as interrelated and integrating realities. We need a shared therapeutic intervention given the complex unity of the human person who is both animated body and incarnated soul. If spirituality is the ability of the human person, to go beyond the constraints of existence, then it has therapeutic effects. In recent decades, health professionals, whether believers or not, have focused on the role of spirituality in health and healing. Many studies have demonstrated the positive influence of spirituality and spiritual life on health and well-being. The majority of the 350 studies that analysed religious beliefs and practice in relation to physical health till the year 2000 revealed that religious or spiritual people are in better physical health lead a healthier lifestyle and are less dependent on health services. Similarly, most of the 850 studies that examined the relationship between religious practice, spirituality, and various aspects of mental health found that people who have some form of religious practice have better mental health and cope with stress more successfully. ${ }^{14}$ Further research on the needs of people with disease has shown that people have greater spiritual needs in times of illness and that taking these needs into account can increase their chances of recovery. Surveys have shown that sick people consider their spiritual health as important as their physical health. ${ }^{15}$ Other studies have focused on the implications of taking into consideration the spiritual needs of sick people and their families for health professionals. ${ }^{16}$ Some scholars have analyzed the ways in which people with severe illness perceive spirituality and religion and adapt to the illness. ${ }^{17}$

\section{Pathogenesis and salutogenesis approaches to public health}

When it comes to public health, both models of pathogenesis and salutogenesis can integrate spirituality into health care. Pathogenesis focuses on factors that cause a disease while salutogenesis focuses on factors that support human health and well-being. In general, scientific studies adopt a pathogenesis approach looking for what caused a disease. For our purpose, it is interesting to know if spirituality plays a protective role against the disease and if the lack of spirituality makes a person more vulnerable to be affected by the disease. Some studies have shown that for patients who define themselves as believers, spirituality has a protective impact against depression, suicide and addiction, thus contributing to their mental health. ${ }^{18}$ Some positive impact of spirituality is also visible in physical health of patients, especially those suffering from cancer and cardiovascular disease. As for the quality of life with less risk to functional decline and cognitive impairment, spirituality plays a protective role. A meta-analysis based on forty-two medical studies correlated the frequency of participation in a religious service with an increase in survival chance. ${ }^{19} \mathrm{~A}$ cohort study ${ }^{20}$ concluded that patients who reported rare or no participation in spiritual activities (prayer, meditation, etc.) were less likely to survive than those who participated more regularly in these spiritual practices. ${ }^{21}$ It is not possible to establish a causal relationship between spirituality and better health. It is unclear as to whether spirituality promotes better health or vice versa. Moreover, it is difficult to identify the factor - whether it is biological, psycho-social or even supernatural that contributes to this correlation. ${ }^{22}$ From an epidemiological point of view, studies affirming the correlation between spirituality and better health are valid. The established epidemiological links pose another question: should they lead the public health services to consider lack of spirituality as a risk factor to act on? Should the preventive measures like campaigns against alcohol, tobacco, sedentary lifestyle and poor nutrition, include campaigns against the lack of spirituality? In other words, is it necessary to proactively prescribe spirituality as suggested by an article that appeared in the New England journal of Medicine? ${ }^{23}$ The absurdity of such medicalization ${ }^{24}$ is obvious. Spirituality would then be manipulative tool in the hands of health professionals to improve health outcomes and contribute to a biomedical rationality desired by the medical world. 
Hence while recognizing a connection between spirituality and health, some authors think that an overly close connection between spirituality and health on the part of health professionals raises ethical issues such as abuse of power, the limits of medical intervention and the possibility of harm. In fact, a physician who gets involved in the spiritual life of his patient and asks him or her questions about his or her spiritual state with a view to making religious recommendations to him or her to improve the therapeutic results, goes beyond his or her authority and the limits of his or her medical intervention. Just as a health professional cannot recommend a patient to get married based on statistical data show that marriage promotes longevity. Too much association between spirituality and beneficial therapeutic effects can be detrimental to some patients who may attribute poor health to moral weakness. According to these authors, given the ethical issues raised it is inappropriate to promote spirituality and religion as adjunctive medical treatments. ${ }^{25}$ From another perspective, health and illness are considered on a continuum. The salutogenesis approach focuses on the factors that support health and well-being, rather than the factors that cause disease. From this perspective, could spirituality move the cursor across the health-disease continuum? It is important to make an analysis that integrates social, cultural and environmental determinants of health. To measure the importance of these determinants, the example of variation in life expectancy according to the place of living is quite compelling. An American study has shown that the residents of Washington DC gain or lose nearly seven years of life expectancy depending on their neighborhood. An even more unequal situation is found in New Orleans where according to neighborhoods, the difference in life expectancy varies approximately twenty-five years. ${ }^{26}$ Even in Switzerland, which has the highest life expectancy among the thirty-four countries in Organization for Economic Co-operation and Development (OECD), life expectancy at age of 30 varies between four and seven years depending on the neighborhood. ${ }^{27}$ This geography of life expectancy aggregates the many determinants identified by the World Health Organization. Some determinants that are difficult to relate include income level and social status, education and literacy, employment and working conditions, social environments, physical environments, health services and gender. Other determinants that are more personal in nature include personal health habits and coping skills, and culture. Determinants that are in personal in nature give rise to what Aaron Antonovsky calls "sense of coherence" 28 that allows us to return to spirituality. The Israeli-American sociologist asks how things that happen to us can make sense and be successfully accounted for. A new resource is available to people who can understand what is happening to them and do something about it, and when they see value in doing so. It is in this "sense of coherence" that spirituality appears to be a resource for healthy life. Considering the spirituality of the patients makes it possible to better understand their expectations and their treatment choices. It also makes it possible to mobilize the so-called "spiritual" resources to better integrate the disease in a continuum. In addition, it contributes to the care ethics by promoting the autonomy of the person, the expression of his or her choices and values. In this regard, a study on the relative importance given to various factors was undertaken through a survey of patients and doctors. At the top of the list for both groups are the recommendations of the doctor. But "faith in God" ranks second for patients while it ranks the last for the doctors. ${ }^{29}$
Public health services are working on disease risk factors within pathogenesis framework. They should also work on the factors of salutogenesis for preserving good health. They need to be coordinated with other services of the State so that all take part in the responsibility of this universal action of promoting good health. In this context, it would also be appropriate to rethink the allocation of resources that shows a huge margin between what makes us healthy and what we really spend on our health. As for the organization of the health care system, it also raises the question of the spirituality of the individual, his or her autonomy, rights, values and dignity. It is the role of public health service to improve the flow of information between all the structures and institutions including hospitals, rehabilitation centers, neighborhood, and healthcare providers by placing the patient at the centre of all decisions of public healthcare. Admittedly, there is no best decision, but it is important to avoid the worst. The objectives of a health care system are to promote an approach centre on the specific needs of the person. In concrete terms, it is primarily about decompartmentalizing institutions and integrating all the partners. It is also important to orient the medical practice not to perpetuate medical institutions but to strengthen the role of the patient in his or her personal journey with an attitude of empowerment. In other words, the medical institution must respond to the needs of the person and not place demand on him or her to adapt to it. Thus, healthcare facilities will be equipped with professionals who are both qualified and transdisciplinary to respect the patient and his or her values throughout the course of health care.

\section{Conclusion}

Spiritual well-being can mean better health outcomes and the benefits of longevity, coping skills, quality of life, and positive attitudes to life. In addition, unresolved problems of spiritual distress can contribute to the deterioration of health status or reduce the chances of recovery, particularly for cancer patients. Paying attention to the spiritual needs of the patients and their families can increase the chances of healing. Health professionals therefore need to show interest in recognizing and catering to the spiritual needs of sick people, which can be done in a respectful and non-controversial way. It should be borne in mind that a health professional would be strongly criticized for transposing or imposing his spiritual gaze or religious beliefs, abusing his authority, violating the rights of his or her patients, and proselytizing. There are many reasons for integrating spirituality into health care services. In the first place, sick people themselves require spiritual care as part of holistic care. Currently, medicine is moving from a disease-centric model to a person-centric model. A holistic conception of health and illness requires an integration of spirituality. Physicians who take time to discern and discover the spiritual needs of sick people, using a "spiritual history". ${ }^{30}$ To establish this spiritual history, Puchalski and Romer ${ }^{31}$ proposed an instrument that has been picked up and modified by other authors like Post, Larson Mueller, Plevak and Rummans. The health professional is invited to ask some questions about what gives meaning to the patient's life especially of a spiritual nature, which the patient can rely on to cope with the illness and difficulties of the patient's existence. These questions are formulated as follows: do you consider yourself spiritual or religious? How important are your beliefs to you and how do you influence your health concerns? Do you belong to a spiritual or religious group or community? How can health professionals help you meet your needs 
in this area? The health professional is not obviously limited to this spiritual history. Other sources of spiritual care such as chaplain, family, friends and community resources can be used. It is first and foremost about promoting dialogue. Including spiritual concerns or needs in one's practice allows the health professional to maximize his or her effectiveness as a therapist.

However, care must be taken in integrating the spiritual dimension into health care. Integrating does not mean replacing. In fact, sick people who require spiritual care require at the same time good diagnoses and the best medical and technological expertise possible. They want a relationship with their doctor or nurse that is marked by respect for their autonomy, open communication, fidelity and uniqueness (of their history and situation). We must also avoid interpreting the contribution of spirituality in health in a causal way. Certainly, prayer is effective, hope heals and despair kills. ${ }^{32}$ But, if religious or spiritual beliefs and practices influence health improvement, healing, struggle or resistance to disease, we do not know if other factors, such as a healthy lifestyle or community support, play an equally important role. What the studies do not suggest is that the so-called religious people are not sick, that the illness is due to a lack of faith, that spirituality is the most important health factor and that doctors must prescribe religious activities. ${ }^{33}$ Finally, we must not ignore that certain religious beliefs or practices can have a negative effect on health, such as the abandonment of effective traditional treatments in the hope of a miraculous cure, the rejection of preventive measures such as immunization vaccines for children, unhealthy guilt or refusal of treatment. ${ }^{34}$ Similarly, over-valuing religious or spiritual practices or beliefs to the detriment of effective therapeutic treatments can lead to manipulation or dependence of the sick person. The integration of spirituality into health care and services, however, requires a clarification of the very concept of spirituality. This is what we have sought to do by proposing a model of description of spirituality. Moreover, a holistic conception of health is not realized in the juxtaposition or sum of the physical, psychological, socio-cultural and spiritual aspects of the human person, but in their integration and harmony. While maintaining an operational distinction between the therapeutic and spiritual fields that each has their "area of relevance," it is a question of associating these approaches by relying on the complementarity of their respective dynamics. If not, there is a danger of confusing the boundaries between these disciplines and risks depreciating the goals of medicine and spirituality. Implementing an integral approach to health and promoting spiritual care is required by the very nature of medicine that has its roots in service and compassion that are spiritual values. Faced with a scientific medicine that has been exercised mainly in the logic of power and technology mastery, considering spirituality gives the opportunity to the medical world to anchor in the real, especially in what is vulnerable, finite, and what cannot be solved. It is a challenge for contemporary medicine to accept the contribution of spirituality to answer the throbbing question of fragility, finitude and helplessness in the face of the excess of suffering. The answer will emerge not so much from an excess of science as from a surplus of the meaning of love.

\section{Acknowledgement}

None

\section{Conflict of interest}

The authors declared that no conflict of interest exists.

\section{References}

1. Daniel P Sulmasy. "A biopsychosocial-spiritual model for the care of patients at the end of life". Gerontologist. 2002;42(3):24-33.

2. Jean-Claude Breton. Pour trouver sa voie spirituelle. 1992. 8 p.

3. See Tonks N. Fawcett and Amy Noble, "The Challenge of Spiritual Care in a Multi-faith Society Experienced as a Christian Nurse". Journal of Clinical Nursing. 2004;13(2):136-142.

4. Antonia M. Van Loon. "Commentary on Fawcett $\mathrm{T}$ and Noble A The challenge of spiritual care in a multi-faith society experienced as a Christian nurse". J Clin Nurs. 2005;14(2):266-268.

5. See Luc Ferry, David Pellauer. Man Made God: Meaning of Life Chicago: University of Chicago Press; 2002.

6. Alan B, Strow A, Christina M, et al."Religion, Spirituality, and Health Care: Social, Ethical, and Practical Considerations". The American Journal of Medicine. 2001;110(4):283-287.

7. Michael Nüchtern. "Critique de la médecine scientifique et attrait des méthodes thérapeutiques 'alternatives' en Occident." Concilium. 1998;278:1-32.

8. Paul Philibert. "Changements de signification de la santé etdes soins de santé”. Concilium. 1998;278:1-19.

9. Cicely M Saunders. "The Philosophy of Terminal Care". The Management of Terminal Illness. 1989:193-202.

10. Bernard Ugeux, Guérir à tout prix? Paris: Editions del'Atelier; 2000. 191 p.

11. Ugeux. Guérir à tout prix. 2017.

12. Raimon Panikkar. "Medicine and Religion". Inter Culture. 2004;27:1-39.

13. Ian G Barbour. Religion and Science: Historical and Contemporary Issues San Francisco. Harper Collins. 1997;77-105.

14. Harold G Koenig. "Religion, Spirituality and Medicine: Application to Clinical Practice". Journal of American Medical Association. 2010;284(13):1708.

15. Paul S Mueller, David J, Plevak, et al. "Religious Involvement, Spirituality, and Medicine: Implications for Clinical Practice. Mayo Clin Proc. 2001;76(12):1225-1235.

16. Stephen G Post, Christina M, Puchalski, David B Larson. "Physicians and Patient Spirituality: Professional Boundaries, Competency, and Ethics". Annals of Internal Medicine. 2000;132(7):578-583.

17. Arndt Büssing, Thomas Ostermann, Peter F Matthiessen. "Role of Religion and Spirituality in Medical Patients: Confirmatory Results with the SpREUK Questionnaire". Health and Quality of Life Outcomes. $2005 ; 10: 3-10$

18. Ellen CF, Idler L, Stanislav V, et al. "Religion among Disabled and Nondisabled Persons II: Attendance at Religious Services as a Predictor of the Course of Disability". The Journals of Gerontology Series B Psychological Sciences and Social Sciences.1997;52(6):306-316.

19. Harold Koenig, David B Larson. "Religion and Mental Health: Evidence for an Association". International Review of Psychiatry. 2001;(3):67-78.

20. Michael Mc Cullough, William T Hoyt, David B, et al. "Religious involvement and mortality: A meta analytic review". Health Psychol. 2000;19(3):211-222.

21. A study design where one or more samples (called cohorts) are followed prospectively and subsequent status evaluations with respect to a disease or outcome are conducted to determine which initial participants exposure characteristics (risk factors) are associated with it. 
22. Hughes M Helm, Judith C Hays, Elizabeth P, et al. "Does Private Religious Activity Prolong Survival? A Six-Year Follow-up Study of 3'851 Older Adults". The Journals of Gerontology Medical Science. 2000;55(7):400-405.

23. Jeffrey S Levin. Religion and Health: is there an Association, is it Valid, and is it Causal. Social Science and Medicine.1994;38(11):1475-1482.

24. Richard P Sloan, Emilia Bagiella, Larry Vandecreek, et al. Should Physicians Prescribe Religious Activities? New England Journal of Medicine. 2000;342(25):1913-1916.

25. Ivan Illich. "The Medicalization of Life". Journal of Medical Ethics. 1975;(1):73-77.

26. Richard P Sloan, Emilia Bagiella, Tia Powell. Religion, Spirituality and Medicine. Lancet. 1999;353(9153):664-667.

27. Robert Wood Johnson Foundation, Commission to Build a Healthie America's City Maps Show Dramatic Differences in Life Expectancy. USA; 2013

28. André Moser, Radoslaw Panczak, Marcel Zwahlen, et al.’What Does Your Neighbourhood Say about You? A Study of Life Expectancy in 1.3 Million Swiss Neighbourhoods". J Epidemiol Community Healt. 2014;68(12):1125-1132.
29. Aaron Antonovsky. The "sense of coherence" is central to successful coping with challenge. Coherence means that the world is understandable, manageable, and meaningful. In this scheme, someone who believes that nature or a divine force is in charge of the world could have a very healthy orientation, even though the individual does not have a personal sense of control. Health Stress and Coping. New Jersey: Jossey-Bass; 1979.

30. Gerard A Silvestri, Sommer Knittig, James Zoller, et al. "Importance of Faith and Medical Decision regarding Cancer Care". J Clin Onco. 2003;21(7):1379-1382.

30 Mueller PS, Plevak DJ, Rummans TA. "Religious Involvement, Spirituality, and Medicine". Mayo Clinic Proceedings. 2001;76(12):1231-1232.

31. Christina M, Puchalski, Anna L Romer. "Taking a Spiritual History Allows Clinicians to Understand Patients More Fully". J Palliat Me. 2000;3(1):129-137.

32. Larry Dossey. Prayer is Good Medicine: How to Reap the Healing Benefits of Prayer? San Francisco: Harper Collins; 1997.

33. Larry May. "Challenging Authority: The Refusal of Treatment by Christian Scientists”. Hastings Center Report. 1995;25:15-22.

34. Neil Soggie. "Living with the "Unfixable". Health Progress. 2003;84:70-72. 